\title{
CORRECTION
}

\section{Correction: A prospective observational study of the relationship of critical illness associated hyperglycaemia in medical ICU patients and subsequent development of type 2 diabetes}

\author{
Ivan Gornik ${ }^{* 1}$, Ana Vujaklija-Brajković, Ivana Pavlić Renar ${ }^{2}$ and Vladimir Gašparović
}

See related research by Gornik et al., http://ccforum.com/content/14/4/R130

After publication of our article [1], a reader noticed that in Figure 1, the number of patients who remained normoglycaemic should be 113, not 133 and the number of patients who developed diabetes should be 33, not 13 . The correct version of the figure is attached overleaf.

\section{Acknowledgements:}

Thanks to Dr Saleh Aldasouqi (Michigan State University College of Human

Medicine) who notifed the authors and journal of the error.

\section{Competing interests}

The authors have no competing interests.

\section{Author details}

'Department of Intensive Care Medicine, University Hospital Centre Rebro, Kispaticeva 12, Zagreb 10000, Croatia. 'Division of endocrinology, Department of Medicine, University Hospital Centre Rebro, Kispaticeva 12, Zagreb 10000, Croatia.

\section{Published: 1 October 2010}

\section{Reference}

1. Gornik I, Vujaklija-Brajković A, Renar IP, Gašparović V: A prospective observational study of the relationship of critical illness associated hyperglycaemia in medical ICU patients and subsequent development of type 2 diabetes. Critical Care 2010, 14:R130.

\section{doi:10.1186/cc9272}

Cite this article as: Gornik l, et al: Correction: A prospective observational study of the relationship of critical illness associated hyperglycaemia in medical ICU patients and subsequent development of type 2 diabetes. Critical Care 2010, 14:444.

Full list of author information is available at the end of the article 


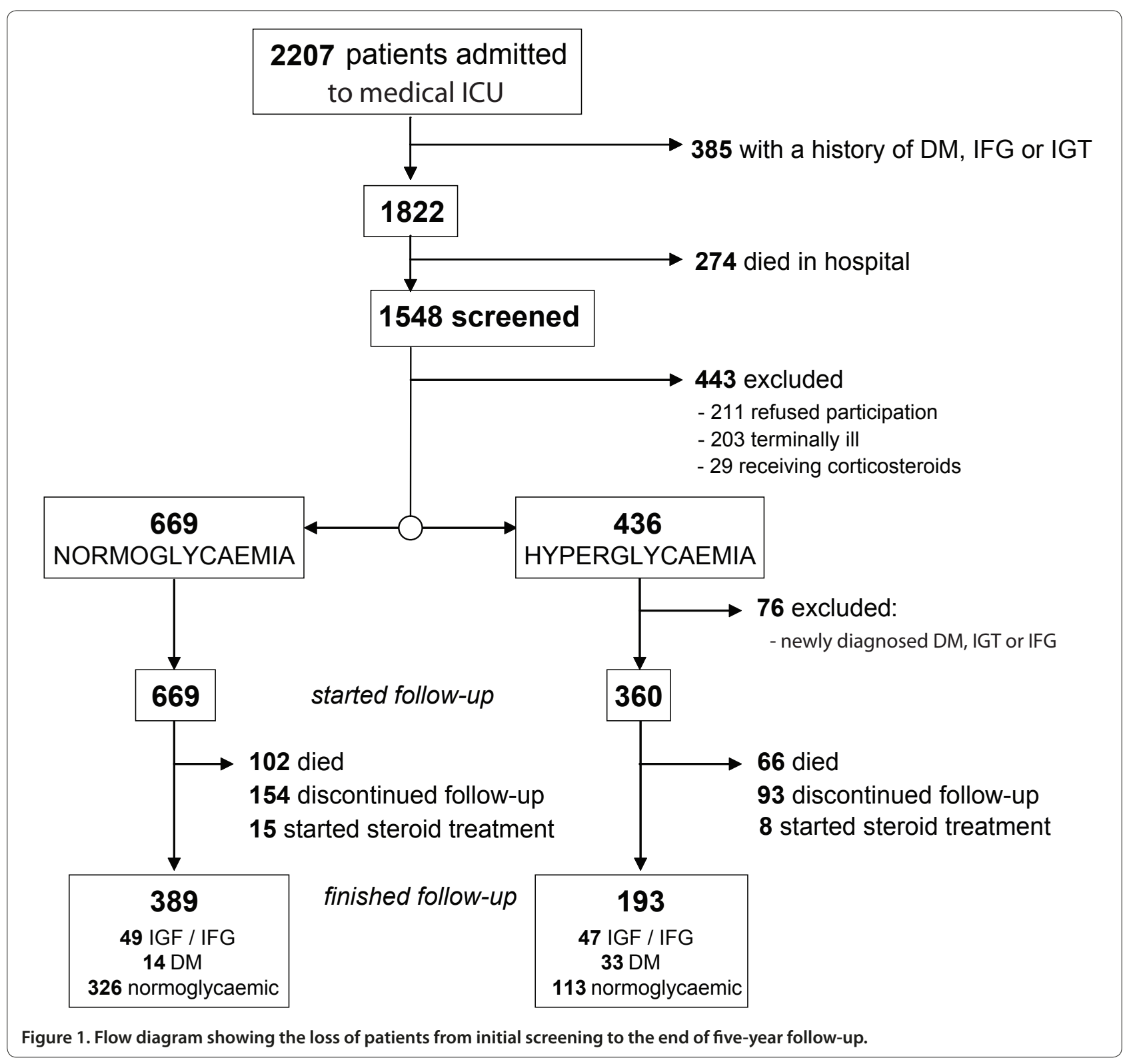

